\title{
Danish and Dutch linguistic validation and cultural adaptation of the WOUND-Q, a PROM for chronic wounds
}

\author{
Tert C. van Alphen ${ }^{1,2,5}$ (D) Lotte Poulsen ${ }^{3}$ • Emiel L. W. G. van Haren ${ }^{2}$ • Amalie L. Jacobsen ${ }^{3}$ • Elena Tsangaris ${ }^{1}$ • \\ Jens A. Sørensen ${ }^{3}$ - Maarten M. Hoogbergen ${ }^{2,4} \cdot$ René R. J. W. van der Hulst ${ }^{5}$. Andrea L. Pusic ${ }^{1} \cdot$ Anne F. Klassen ${ }^{6}$
}

Received: 16 December 2018 / Accepted: 1 February 2019 / Published online: 10 May 2019

(C) The Author(s) 2019

\begin{abstract}
Chronic wounds represent a significant problem to patients, healthcare professionals, and healthcare systems alike. The inclusion of patient-reported outcome measures (PROMs) into wound care outcome assessment will provide important information. The WOUND-Q is a new PROM developed to measure outcomes for people with chronic wounds. This study aimed to perform a linguistic validation/cultural adaption of the WOUND-Q from English into Danish and Dutch. The field-test version of the WOUND-Q is a comprehensive PROM composed of 222 items in 16 independently functioning scales. We followed the rigorous guidelines set forth by the International Society for Pharmacoeconomics and Outcomes Research (ISPOR) and the World Health Organization (WHO). These guidelines involved two forward translations, one back translation, an expert panel meeting, and cognitive debriefing interviews with patients. In the forward translation, the psychological function scale showed the greatest number of discrepancies from the English version. Comparison of the back translation of the Danish and Dutch versions with the English version identified 19 and 24 items respectively where the meaning had changed and required re-translation. A total of 38 cognitive debriefing interviews resulted in minor adjustments and demonstrated that the questionnaire had sufficient comprehensibility. The linguistic validation and cultural adaptation process is an essential step to adapting PROMs for use in other languages and cultures. The described method of translation and linguistic validation can be recommended for future translations of any PROM into any target language. The translation process led to conceptually equivalent Danish and Dutch versions of the WOUND-Q.
\end{abstract}

Level of Evidence: Not ratable.

Keywords Translation $\cdot$ Cultural adaption $\cdot$ Linguistic validation $\cdot$ Patient-reported outcome $\cdot$ PROM $\cdot$ Chronic wound

Tert C. van Alphen

tertvanalphen@live.nl

1 Patient-Reported Outcomes, Value \& Experience (PROVE) Center, Brigham and Women's Hospital, Harvard Medical School, Boston, MA, USA

2 Department of Plastic Surgery, Catharina Ziekenhuis, Eindhoven, The Netherlands

3 Department of Plastic Surgery, Odense University Hospital and OPEN, Odense Patient data Explorative Network, 5000 Odense, Denmark

4 Da Vinci Kliniek, Geldrop, The Netherlands

5 Department of Plastic Surgery, Maastricht University Medical Center + , Maastricht, The Netherlands

6 Department of Pediatrics, McMaster University, Hamilton, Ontario, Canada

\section{Introduction}

Chronic wounds represent a significant health problem and challenge to patients, healthcare professionals, and healthcare systems alike. Chronic wounds are defined as wounds that fail to heal within 3 months [1]. The most common chronic wounds are pressure ulcers, diabetic foot ulcers, venous stasis wounds, and ischemic wounds of arterial or post-irradiation etiology [2, 3]. Millions of patients worldwide require treatment for chronic wounds each year. Wound treatment often requires a multidisciplinary care team approach, since patients often present with comorbidities that can affect wound healing [3-5]. The impact of chronic wounds on patients varies greatly with respect to recovery, return to usual activities, as well as health-related quality of life (HR-QoL) [6-8]. 
Traditionally, wound assessments have been performed using objective measures such as their incidence, rate of healing, wound reduction, and complication rates [9-11]. However, the use of objective measures alone neglects the patient perspective of their outcomes. Since recent literature has shown that psychological and social aspects, HR-QoL, and experience of care are significant contributors to a patients' overall experience of chronic wounds, the inclusion of a patient-reported outcome measure (PROM) in wound care outcome assessments could provide supplementary data about the patient experience of wound care treatments and their outcomes $[10,12,13]$.

Generic PROMs, such as the SF-36 and Quality of Life Index, have been used widely to characterize the patient's perspective in many contexts (e.g., population surveys) and for many conditions $[14,15]$. However, generic tools are not clinically contextualized and do not measure concepts of interest (COI) specific to chronic wound patients and therefore lack content validity in this patient group. Specifically, relevant COI to patients with chronic wounds that are not covered by generic tools include concerns about odor and exudate and dressing changes [16]. Recent systematic reviews on venous leg ulcers and pressure ulcers conclude that the generic and chronic woundspecific instruments are limited in terms of content and psychometric properties [12, 17-19].

The WOUND-Q is a new PROM developed following a 3-phased mixed method approach that adheres to recommended guidelines from the US Food and Drug Administration (FDA) [20], the Scientific Advisory Committee of the Medical Outcomes Trust [21], the International Society for Pharmacoeconomics and Outcomes Research [22, 23], and the COnsensus-based Standards for the selection of health status Measurement
INstruments (COSMIN) [24]. The WOUND-Q was developed following interviews with an international heterogeneous sample of 60 patients with chronic wounds and input from 26 clinical experts from four countries. The WOUND-Q includes 16 independently functioning scales that measure HR-QoL and experience of healthcare.

Our team has previously shown that a combination of the guidelines set forth by the International Society for Pharmacoeconomics and Outcomes Research (ISPOR) and the World Health Organization (WHO) provides a sound basis for this linguistic validation and cultural adaptation process [25-27]. This study aimed to produce Danish and Dutch versions of WOUND-Q that are conceptually equivalent to the original English version.

\section{Materials and methods}

Before initiating the study, we obtained approval from the Danish Data Protection Agency and the Dutch Medical Research Ethics Committees United (MEC-U). We followed a combination of the ISPOR and WHO guidelines $[25,26]$. See Table 1 for the steps of each guideline. In addition to the ISPOR guidelines, the WHO recommends an expert panel meeting that aims to identify and resolve inadequate expressions and concepts of the translation, as well as any discrepancies. The panel is recommended to involve experts who are bilingual including translators, and clinical experts in the health field for which the instrument is being translated, as well as PROM experts with knowledge of instrument development and validation.

The field-test version of the WOUND-Q included 230 items across 16 scales. Translations were performed
Table 1 Translation steps of the ISPOR and WHO guidelines

\begin{tabular}{lll}
\hline Step & ISPOR & WHO \\
\hline 1 & Preparation & Forward translation \\
2 & Forward translation & Back translation \\
3 & Reconciliation & Prert panel \\
4 & Back translation & Final version \\
5 & Back translation review & \\
6 & Harmonization & \\
7 & Cognitive debriefing & \\
8 & Review of cognitive debriefing results & \\
9 & Proofreading & \\
10 & Final report & \\
\hline
\end{tabular}

ISPOR: International Society for Pharmacoeconomics and Outcomes Research; WHO: World Health Organization 
to prepare for an international field-test study. We aimed to create conceptually equivalent translations that would be understandable to patients, rather than literal translations. The following steps were taken for the Danish and Dutch translation of WOUND-Q (see also Fig. 1):

\section{Step 1. Forward translation}

Two forward translations were performed independently by the Danish and Dutch teams. For each language, a translator with clinical experience with chronic wounds performed a forward translation. Both forward translators spoke Danish/ Dutch as their mother tongue and were fluent in English. Consensus was reached through reconciliation and discussion between the two forward translators resulting in the Danish/ Dutch version 1.

\section{Step 2. Backward translation and review}

An independent professional translator, whose mother tongue was English and was fluent in Danish/Dutch, produced the back translation from Danish/Dutch into English. Discrepancies between the back translations and the original English version were noted and discussed with the WOUND-Q developers (AP, AK). In an iterative manner, items from the back translation with a meaning that was different from the English version were re-translated and discussed with the developers. This step continued until a satisfactory result was obtained, leading to the Danish/Dutch version 2.

\section{Step 3. Expert panel meeting}

The aim of the expert panel meeting was to identify and resolve any inadequate expressions and concepts in the translation, and to ensure that the instrument itself measured all clin- ically relevant issues from the perspective of the clinicians. The Danish/Dutch versions of the WOUND-Q, along with translation guidelines, were sent to all participants prior to the meeting. Feedback was used to revise the PROM, which led to the Danish/Dutch version 3.

\section{Step 4. Cognitive debriefing interviews}

Using the Danish/Dutch version 3, cognitive debriefing interviews (round 1) were performed with patients with chronic wound to ensure that the meanings of the items, response options, and instructions were the same as the original English version and were easy to understand. In both Denmark and the Netherlands, one of the forward translators conducted the cognitive debriefing interviews in their respective countries. Results from the cognitive debriefing interviews were discussed with the WOUND$\mathrm{Q}$ developers, and changes to the translations were made as needed. Additional cognitive debriefing interviews (round 2) were conducted to ensure all changes were acceptable to patients leading to the Danish/Dutch version 4.

\section{Step 5. Proofreading and finalization}

The Dutch/Danish versions were proofread by independent Danish/Dutch clinicians for spelling and grammatical errors, leading to the final Danish/Dutch versions of the WOUND-Q.

\section{Results}

\section{Results from the forward translations of the WOUND-Q into Danish and Dutch}

Findings from the forward translation showed that the two Dutch translators had different interpretations of the

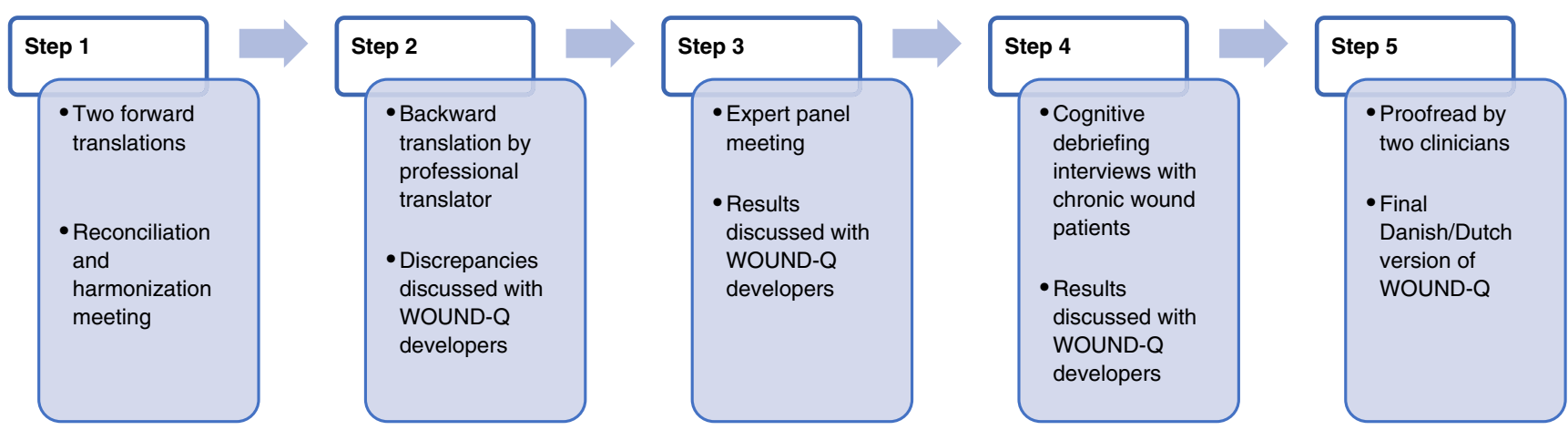

Fig. 1 Translation and cultural adaptation steps for the WOUND-Q 
Table 2 Patient characteristic participating in the cognitive debriefing interviews

\begin{tabular}{|c|c|c|c|c|}
\hline & \multicolumn{2}{|c|}{ Denmark } & \multicolumn{2}{|c|}{ The Netherlands } \\
\hline & $N$ & $\%$ & $N$ & $\%$ \\
\hline Participants in cognitive debriefing interviews & 22 & & 16 & \\
\hline Round 1 & 18 & & 5 & \\
\hline Round 2 & 4 & & 11 & \\
\hline Age in years. mean (range) & 61 & $28-78 \mathrm{y}$ & 61 & $38-85$ y \\
\hline \multicolumn{5}{|l|}{ Gender } \\
\hline Male & 16 & 72.7 & 7 & 43.8 \\
\hline Female & 6 & 27.3 & 9 & 56.3 \\
\hline \multicolumn{5}{|l|}{ Number of chronic wounds } \\
\hline 1 & 13 & 59.1 & 12 & 75.0 \\
\hline 2 & 7 & 31.8 & 3 & 18.8 \\
\hline 3 & 1 & 4.5 & 1 & 6.3 \\
\hline$>3$ & 1 & 4.5 & 0 & 0 \\
\hline \multicolumn{5}{|l|}{ Duration of chronic wound(s) } \\
\hline 3 to 6 months & 13 & 59.1 & 7 & 43.8 \\
\hline 7 to 9 months & 2 & 9.1 & 4 & 25.0 \\
\hline 10 to 12 months & 3 & 13.6 & 0 & 0 \\
\hline 1 or 2 years & 1 & 4.5 & 4 & 25.0 \\
\hline 2 or 3 years & 1 & 4.5 & 0 & 0 \\
\hline More than 3 years & 2 & 9.1 & 1 & 6.3 \\
\hline \multicolumn{5}{|l|}{ Type of chronic wound } \\
\hline Arterial ulcer & 2 & 9.1 & 0 & 0 \\
\hline Venous ulcer & 1 & 4.5 & 0 & 0 \\
\hline Diabetic foot ulcer & 7 & 31.8 & 6 & 37.5 \\
\hline Pyoderma gangrenosum & 0 & 0 & 1 & 6.3 \\
\hline Pilonidal cyst/disease & 0 & 0 & 2 & 12.5 \\
\hline Pressure ulcer & 4 & 18.1 & 3 & 18.7 \\
\hline Wound caused by surgery & 2 & 9.1 & 0 & 0 \\
\hline Wound caused by radiation & 0 & 0 & 2 & 12.5 \\
\hline Wound caused by trauma or injury & 5 & 23.0 & 2 & 12.5 \\
\hline Infection & 1 & 4.5 & 0 & 0 \\
\hline \multicolumn{5}{|l|}{ Location of wound } \\
\hline Arm & 0 & 0 & 1 & 6.3 \\
\hline Chest & 0 & 0 & 2 & 12.5 \\
\hline Abdomen & 1 & 4.5 & 0 & 0 \\
\hline Back & 0 & 0 & 2 & 12.5 \\
\hline Buttocks (bum) & 1 & 4.5 & 0 & 0 \\
\hline Genitals & 0 & 0 & 2 & 12.5 \\
\hline Leg & 2 & 9.1 & 9 & 56.3 \\
\hline Foot & 12 & 54.5 & 0 & 0 \\
\hline Toe(s) & 6 & 27.3 & 0 & 0 \\
\hline
\end{tabular}


language, which required discussion to reach consensus. For example, the use of formal versus informal language to address patients and certain medical terminology were key differences between the translations that needed to be addressed. A total of six items were found difficult to translate into either Danish or Dutch. Discussion with the WOUND-Q developers resulted in these items being deleted from the original and target language versions.

The psychological function scale showed the greatest number of discrepancies due to synonymous words that are used to describe different emotions. For example, the emotions "worried" and "concerned" and "irritated" and "annoyed" were difficult to translate into Danish and Dutch because of their similarity in meaning in the target languages, leading to their removal of four items in the English version and both translations. Also removed were two items related to the co-payment of dressings and vacuum pump devices, which is not relevant in Denmark and the Netherlands given that patients are seldom asked to co-pay for these products.

\section{Results from backward translation into Danish and Dutch}

By comparing the back translations of the Danish and Dutch versions to the original English version of WOUND-Q, the developers identified 19 and 24 items respectively (7 common to both) whose meaning differed from the English version. These items were retranslated iteratively until a satisfactory translation was reached. For example, the Danish translation of the item "How painful your wound feels?" was initially backtranslated as "Pain from your wound?" A further example was the Dutch translation of the item "the smell interfering with your social life" that was backtranslated as "the smell influencing your social life." These items were considered to differ in meaning from the original English items and required revision.

\section{Results from the expert panel meeting of the Danish and Dutch teams}

The Danish expert panel consisted of the two forward translators, the back translator, a plastic surgeon specialized in chronic wounds, an orthopedic surgeon specialized in chronic foot ulcers, and a nurse with expertise in wound care. All participants spoke Danish as their mother tongue and were fluent in English, except for the back translator who had English as his mother tongue and the plastic surgeon who was bilingual. The
Dutch expert panel consisted of the two forward translators, a plastic surgeon specialized in wound care, a vascular surgeon specialized in diabetic foot and chronic wound ulcers, a doctor specialized in hyperbaric oxygen therapy and wound care, and a nurse specialized in wound care. All participants spoke Dutch as their mother tongue and were fluent in English, except the doctor specialized in hyperbaric oxygen therapy who was bilingual. The Danish and Dutch expert panel resulted in a total of 24 items, 12 in each language, being revised to simplify and remove unnecessary medical terms to improve comprehension of items and instructions.

\section{Results from cognitive debriefing interviews with Dutch and Danish chronic wound patients}

Cognitive debriefing interviews involved a heterogeneous group of 38 participants, 22 from Denmark and 16 from the Netherlands. See Table 2 for patient characteristics. The Danish and Dutch cognitive debriefing interview resulted in 11 items and the instructions being revised to improve relevance and comprehension by patients. For example, in the "Experience: Wound Clinic" scale, the item "had enough healthcare staff" was deleted from the scale since patients from Denmark found this item difficult to rate. Waiting time is sometimes not directly correlated to the number of staff, and you need a gold standard/reference clinic to compare.

\section{Results from the proofread}

Minor changes to spelling, punctuation, and grammar were made upon final proofreading of both the Dutch and Danish versions.

Tables 3 and 4 for the Danish and Dutch translations, respectively, provide examples of the discrepancies and changes addressed throughout the translation process. The final version of the WOUND-Q consists of 16 independently functioning scales with 222 items. See Table 5 for an overview of the WOUND-Q scales and their associated number of items.

\section{Discussion}

Linguistic validation and cultural adaptation of a PROM for use in a new culture is time-consuming and requires input from multiple stakeholders using an iterative approach. To achieve the most accurate Danish and Dutch translations of the WOUND-Q, we followed the guidelines set forth by the ISPOR and WHO $[25,26]$. A total 


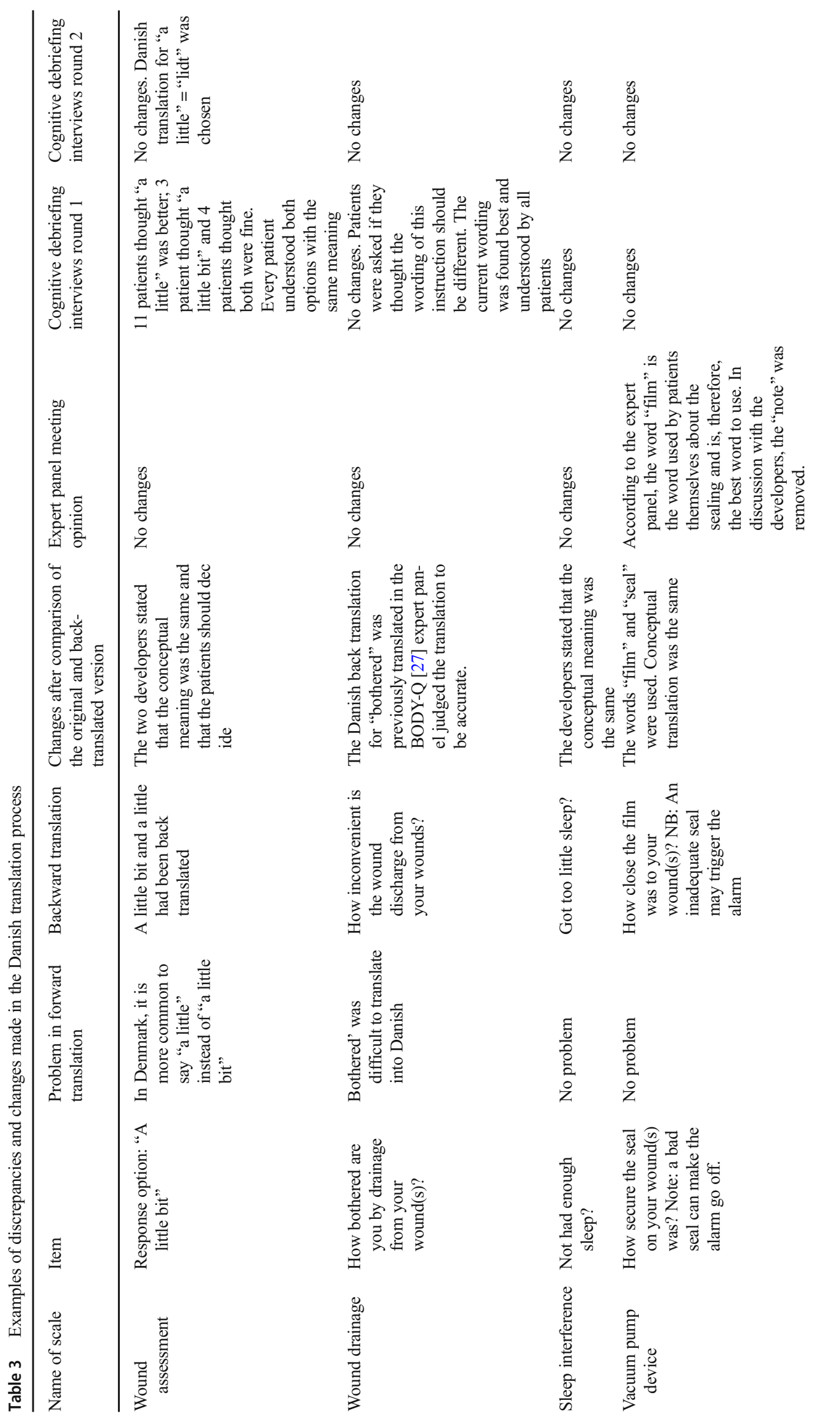




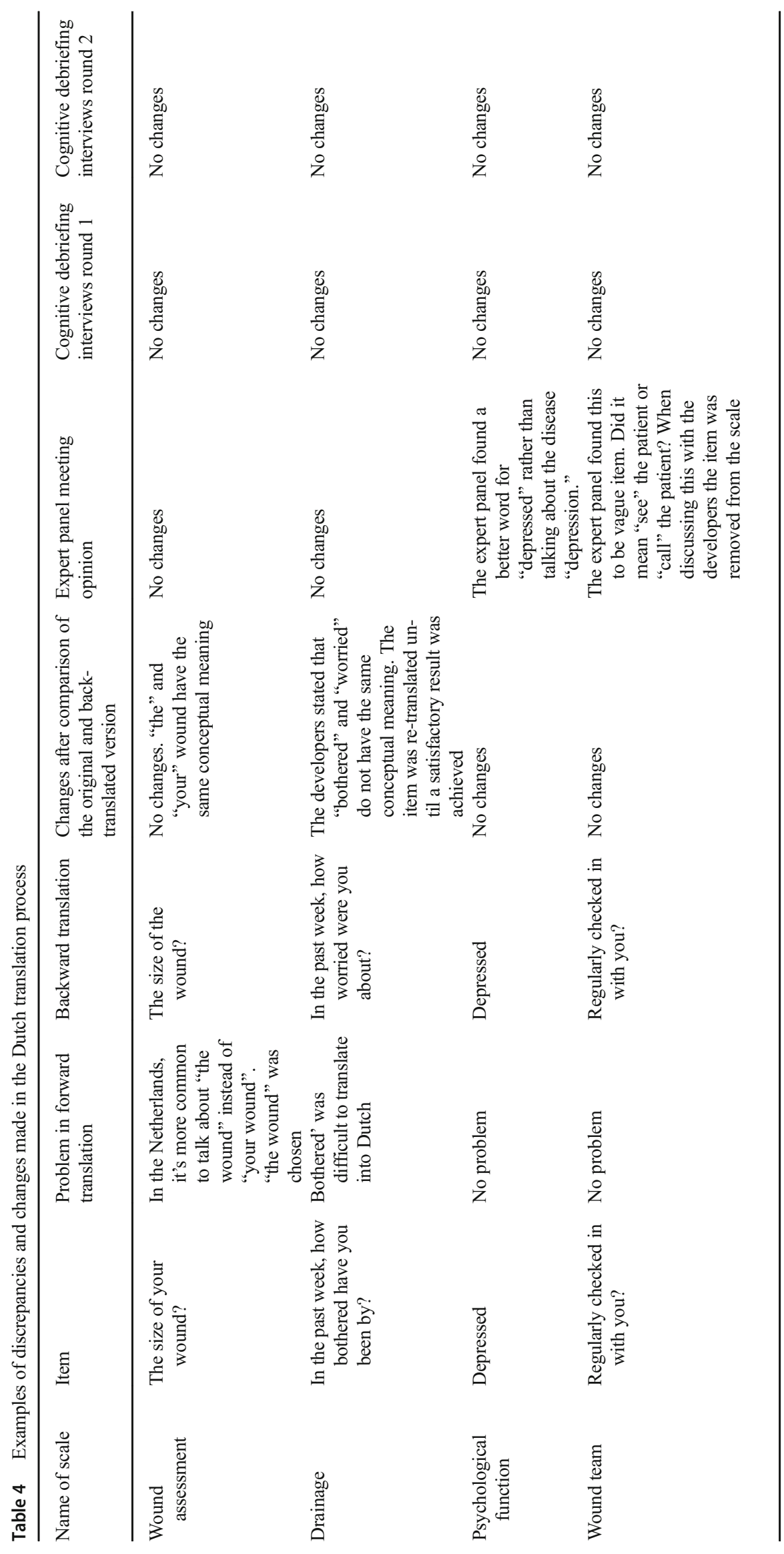


Table 5 Overview of WOUND-Q scales

\begin{tabular}{lll}
\hline & Response option & \# items \\
\hline Outcome scales & & \\
Wound assessment & Frequency & 17 \\
Wound drainage & Frequency & 10 \\
Wound smell & Frequency & 9 \\
Sleep interference & Frequency & 8 \\
Psychological function & Frequency & 17 \\
Quality of life & Frequency & 13 \\
Social function & Agree/disagree & 11 \\
Work impact & Agree/disagree & 10 \\
Wound acceptance & Agree/disagree & 8 \\
& & \\
Experience scales & & 19 \\
Information & Satisfaction & 21 \\
Home care & Agree/disagree & 28 \\
Wound team & Agree/disagree & 14 \\
Office staff at the wound clinic & Agree/disagree & 13 \\
Wound clinic & Agree/disagree & 9 \\
Wound dressing & Satisfaction & 15 \\
Vacuum pump device & Satisfaction & \\
\hline
\end{tabular}

of 8 items were deleted as a result of the linguistic validation and cultural adaptation process. Our findings illustrate the advantage of gaining input from different cultural and linguistic backgrounds before finalizing the original source PROM. This approach made it possible to use the findings, found in the translation phase, to adjust the English version at the same time.

Prior to beginning the translation work, our team discussed the steps from the two guidelines that would provide the most robust translation. For instance, the WHO guideline recommends one forward translation, whereas the ISPOR guideline recommends two independent forward translations followed by reconciliation and harmonization meeting to achieve agreement. We followed the ISPOR guidelines for forward translations given they were more rigorous. Furthermore, the WHO guideline suggests an expert panel meeting as part of the translation process, which we included since it was considered to be a useful step to reduce unnecessary medical jargon and enhance the comprehensibility of the final versions $[25,26]$.

We followed a robust methodology reflecting the principles of good practice for translation of PROMs using a combination of the ISPOR and WHO guidelines $[25,26]$. An additional strength of our study was that the cognitive debriefing interviews included a large sample of patients. The ISPOR guidelines recommend 5 to 8 cognitive interviews, while the WHO guidelines recommend a minimum of 10 [25, 26]. We performed 38 (22 in Denmark and 16 in the Netherlands) cognitive debriefing interviews to ensure that patients with a variety of chronic wound types provided feedback on the scales. Feedback from patients was crucial to improve the readability and comprehensibility of the Danish and Dutch versions of the WOUND-Q.

Our study has some limitations. First, patients in the cognitive debriefing interviews tended to have chronic wounds located on their feet and toes, with only a few participants with wounds on other parts of the body. However, our sample represented the natural distribution of our chronic wound patient population in both Denmark and the Netherlands. Second, there was a difference in the number of cognitive debriefing interviews performed in round 1 and round 2 between the Danish and Dutch group. Despite the smaller Dutch sample group, no new issues with comprehensibility were expressed by the Dutch patients.

\section{Conclusions}

Our team performed a linguistic validation and cultural adaptation of the WOUND-Q into Danish and Dutch and tested its comprehensibility and cultural relevance in a group of chronic wound patients in both countries. The ISPOR and WHO guidelines provided a rigorous framework for translation and led to a conceptual, rather than literal translation of the original WOUND-Q. Our findings helped to identify items that were difficult to translate and therefore dropped from original source PROM prior to field-testing. The described method of linguistic validation and cultural adaptation can be recommended for future translations of the WOUND-Q and other PROMs.

\section{Compliance with ethical standards}

Before initiating the study, we obtained approval from the Danish Data Protection Agency and the Dutch Medical Research Ethics Committees United (MEC-U).

Conflict of interest A.F. Klassen and A.L. Pusic who are codevelopers of the WOUND-Q could potentially receive a share of any license revenues as royalties based on their institution's inventor sharing policy. The remaining authors have no financial disclosures. 
Ethical approval All procedures performed in studies involving human participants were in accordance with the ethical standards of the institutional and/or national research committee and with the 1964 Helsinki declaration and its later amendments or comparable ethical standards.

Informed consent Informed consent was obtained from all individual participants included in the study.

Funding sources This research is funded by the Plastic Surgery Foundation.

Open Access This article is distributed under the terms of the Creative Commons Attribution 4.0 International License (http:// creativecommons.org/licenses/by/4.0/), which permits unrestricted use, distribution, and reproduction in any medium, provided you give appropriate credit to the original author(s) and the source, provide a link to the Creative Commons license, and indicate if changes were made.

\section{References}

1. Mustoe TA, O’Shaughnessy K, Kloeters O (2006) Chronic wound pathogenesis and current treatment strategies: a unifying hypothesis. Plast Reconstr Surg 117(7S):35S-41S

2. Jones CM, Rothermel AT, Mackay DR (2017) Evidence-based medicine: wound management. Plast Reconstr Surg 140(1):201e$216 \mathrm{e}$

3. Fife CE, Carter MJ, Walker D, Thomson B (2012) Wound care outcomes and associated cost among patients treated in US outpatient wound centers: data from the US wound registry. Wounds 24(1):10-17

4. Gottrup F (2004) A specialized wound-healing center concept: importance of a multidisciplinary department structure and surgical treatment facilities in the treatment of chronic wounds. Am J Surg 187(5A):38S-43S

5. Sen CK, Gordillo GM, Roy S, Kirsner R, Lambert L, Hunt TK, Gottrup F, Gurtner GC, Longaker MT (2009) Human skin wounds: a major snowballing threat to public health and economy. Wound Repair Regen 17(6):763-771

6. McCaughan D, Sheard L, Cullum N, Dumville J, Chetter I (2018) Patients' perceptions and experiences of living with a surgical wound healing by secondary intention: a qualitative study. Int $\mathrm{J}$ Nurs Stud 77:29-38

7. Gorecki C, Brown JM, Nelson EA, Briggs M, Schoonhoven L, Dealey C, Defloor T, Nixon J, on behalf of the European Quality of Life Pressure Ulcer Project group (2009) Impact of pressure ulcers on quality of life in older patients: a systematic review. J Am Geriatr Soc 57(7):1175-1183

8. Price P, Krasner D (2012) Health-related quality of life and chronic wounds: evidence and implications for practice. In: Chronic wound care: a clinical source book for healthcare professionals, 5th edn. HMP Communications, Malvern, pp $77-84$

9. Nixon J, Cranny G, Iglesias C, Nelson EA, Hawkins K, Phillips A, Torgerson D, Mason S, Cullum N (2006) Randomised, controlled trial of alternating pressure mattresses compared with alternating pressure overlays for the prevention of PRESSURE ulcers: PRESSURE (pressure relieving support surfaces) trial. BMJ 332(7555):1413-1415
10. Gottrup F, Apelqvist J, Price P (2010) European Wound Management Association Patient Outcome Group. Outcomes in controlled and comparative studies on non-healing wounds: recommendations to improve the quality of evidence in wound management. J Wound Care 19(6):237-268

11. Soon SL, Chen SC (2004) What are Wound Care Outcomes? Wounds 16(5)

12. Gorecki C, Nixon J, Lamping DL, Alavi Y, Brown JM (2014) Patient-reported outcome measures for chronic wounds with particular reference to pressure ulcer research: a systematic review. Int J Nurs Stud 51(1):157-165

13. Black N (2013) Patient reported outcome measures could help transform healthcare. BMJ 346:f167

14. Ware JE, Sherbourne CD (1992) 36-item short-form health survey (SF-36). I. Conceptual framework and item selection. Med Care 30(6):473-483

15. Ferrans CE, Powers MJ (1985) Quality of life index: development and psychometric properties. ANS Adv Nurs Sci 8(1):15-24

16. Halcon L, Lillehei A, Melin MM, Shapiro A, Robinson C (2016) Wound care: multicenter feasibility study. Adv Skin Wound Care 29(1):26-31

17. González-Consuegra RV, Verdú J (2011) Quality of life in people with venous leg ulcers: an integrative review. J Adv Nurs 67(5): 926-944

18. Palfreyman SJ, Tod AM, Brazier JE, Michaels JA (2010) A systematic review of health-related quality of life instruments used for people with venous ulcers: an assessment of their suitability and psychometric properties. J Clin Nurs 19(1920):2673-2703

19. Poku E, Aber A, Phillips P, Essat M, Buckley Woods H, Palfreyman $S$ et al (2017) Systematic review assessing the measurement properties of patient-reported outcomes for venous leg ulcers. BJS Open 1(5):138-147

20. U.S. Department of Health and Human Services Food and Drug Administration (2009) Guidance for industry. Use in medical product development to support labeling claims guidance for industry. Clinical/Medical Federal Register:1-39

21. Aaronson N, Alonso J, Burnam A, Lohr KN, Patrick DL, Perrin E et al (2002) Assessing health status and quality-oflife instruments: attributes and review criteria. Qual Life Res 11(3):193-205

22. Patrick DL, Burke LB, Gwaltney CJ, Leidy NK, Martin ML, Molsen E, Ring L (2011) Content validity-establishing and reporting the evidence in newly developed patient-reported outcomes (PRO) instruments for medical product evaluation: ISPOR PRO good research practices task force report: part $1-$ eliciting concepts for a new PRO instrument. Value Health 14(8):967-977

23. Patrick DL, Burke LB, Gwaltney CJ, Leidy NK, Martin ML, Molsen E, Ring L (2011) Content validity-establishing and reporting the evidence in newly developed patient-reported outcomes (PRO) instruments for medical product evaluation: ISPOR PRO good research practices task force report: part 2 assessing respondent understanding. Value Health 14(8):978988

24. Reeve BB, Wyrwich KW, Wu AW, Velikova G, Terwee CB, Snyder CF, Schwartz C, Revicki DA, Moinpour CM, McLeod LD, Lyons JC, Lenderking WR, Hinds PS, Hays RD, Greenhalgh J, Gershon R, Feeny D, Fayers PM, Cella D, Brundage M, Ahmed S, Aaronson NK, Butt Z (2013) ISOQOL recommends minimum standards for patient-reported outcome measures used in patient-centered outcomes and comparative effectiveness research. Qual Life Res 22(8):1889-1905 
25. Wild D, Grove A, Martin M, Eremenco S, McElroy S, VerjeeLorenz A, Erikson P, ISPOR Task Force for Translation and Cultural Adaptation (2005) Principles of good practice for the translation and cultural adaptation process for patient-reported outcomes (PRO) measures: report of the ISPOR task force for translating adaptation. Value Health 8(2):94-104

26. WHO (World Health Organization). Process of translation and adaptation of instruments. [Internet]. [cited 2019 Apr 1]. Available from: http://www.who.int/substance_abuse/research_tools/ translation/en/
27. Poulsen L, Rose M, Klassen A, Roessler KK, Sørensen JA (2017) Danish translation and linguistic validation of the BODY-Q: a description of the process. Eur J Plast Surg 40(1):29-38

Publisher's note Springer Nature remains neutral with regard to jurisdictional claims in published maps and institutional affiliations. 